\title{
A renewal approach with variable number of promotion and recruitment in a graded manpower system with double jump
}

Nwaigwe, Chrysogonus Chinagorom

Department of Statistics, Federal University of Technology Owerri, Imo State, Nigeria

Email address:

chrysogonusnwaigwe@yahoo.com

To cite this article:

Nwaigwe, Chrysogonus Chinagorom. A Renewal Approach with Variable Number of Promotion and Recruitment in A Graded Manpower System with Double Jump. Journal of Human Resource Management. Vol. 2, No. 2, 2014, pp. 33-41. doi: 10.11648/j.jhrm.20140202.11

\begin{abstract}
The use of the Renewal approach for the prediction of flows, entries and grade sizes as well as for control in systems where movement is restricted only to, the next higher level has been studied by many; promotions and recruitments were defined as expected numbers rather random numbers whereas, in reality, promotions and recruitments are often random variables. Few works on Renewal approach for a manpower system with double jump have assumed that promotion and recruitment are expected numbers. In the present work, we define promotions and recruitments as random variables and obtain their expectations and variances in a manpower system with single and double jumps.
\end{abstract}

Keywords: Renewal Approach, Random Promotion, Random Recruitment, Expectations and Variances, Double Jump

\section{Introduction}

Graded systems may be modeled in order to predict flows of units into and within the system or losses from the system. In some systems, a flow of a unit from outside the system to the system may occur in any level or be restricted to some levels. On the other hand, when units flow within the system, they may move from a lower level to the next higher level or have a double jump. For example, in most insurance companies where hard work other than length of service is rewarded, the movement of employees from a lower level to the second higher level (double jump) is common. Also in the university system, some lecturers move from the position of senior lecturer to professor when they obtain the qualifications for the promotion after a long stay in the second lower grade. It was observed in [1] that the Renewal model differs from the Markov and semiMarkov models by incorporating job vacancies as promotion opportunities. Using a Renewal model of the

form $p_{i, i+1}^{-}=\frac{\sum_{j=i+1}^{k} n_{j}(t) p_{j, k+1}^{-}+\bar{v}_{j}(t)}{\overline{n_{i}(t)}}$ where $\bar{p}_{i, i+1}(t)$ is the expected promotion probability from grade $i$ to grade $i+1$, $\bar{n}_{j}(t)$ is the expected number of employees in grade $\mathrm{j}$, $p_{j, k+1}$ is the expected probability of loss and $\bar{v}_{j}(t)$ is the expected number of new jobs created in grade $j$, he compared the predictive utility of the Markov model, semiMarkov model and a Renewal model for long term cohort forecast and long term organizational forecasts. $\mathrm{He}$ concluded that the best model for intermediate ( 5 years) and long term (10 years) forecasts in both cohorts and organizational tests is the Renewal type vacancy model. The above Renewal model, assumes that promotion occurs from a lower level to the next higher. A manpower system that restricts recruitment to the lowest grade was discussed in [2]. Equations of the type,

$$
\begin{aligned}
& x_{3}(t+1)=x_{3}(t)+f_{2,3}(t+1)-w_{3}(t) \\
& x_{2}(t+1)=x_{2}(t)-f_{2,3}(t+1)+f_{1,2}(t+1)-w_{2}(t) \\
& x_{1}(t+1)=x_{1}(t)-f_{1,2}(t+1)+h(t)-w_{1}(t)
\end{aligned}
$$

Where the subscripts in $\mathrm{x}$ denote the desired number in each state at a given time, the $f$-variables denote the expected promotions between the states at the given time, the $w^{\prime} s$ refer to the wastage levels at the given state and time while $\mathrm{h}(\mathrm{t})$ refers to new employees were obtained. According to [3], the Renewal theory is seen to be an appropriate tool for studying transitions in certain graded social processes. The Renewal theory was used to fit some distributions to data on length of service and the 
approximate values of the Renewal equations and the rate of withdrawal at time $t$ were obtained.

Renewal processes were applied in [3] to forecast the manpower losses of an organization in order to determine whether the organization will be able to meet its demand for manpower under prevailing conditions. An equation of the form $H(t)=\int_{0}^{t} n(s) h(t-s) d s$, where $H(t)$ is the expected number of replacements, $n(t)$ is the organization size at time $\mathrm{t}, h(t)$ is the renewal density was used. The results showed that certain problems may arise in terms of quality of manpower because of high turnover rate. His discussion did not involve how the losses should be replaced. Similarly, a three-grade Renewal model in which promotion occurs only to the next higher grade level was described in [5]. Predictive equations of the forms,

$$
\begin{gathered}
p_{i, i+1}=\left(n_{i+1} w_{i+1}+p_{i+1, i+2}\right) s_{i+1}, i=1,2, \ldots, k-2 \text { and } \\
R_{i}=n_{i} w_{i}+p_{i, i+1}-p_{i-1, i}
\end{gathered}
$$

Were obtained for promotion from grade level $i$ to $i+1$ and recruitment into grade level i respectively, where the subscripts in $\mathrm{n}$ represent the known grade sizes, the subscripts in $\mathrm{w}$ represent the wastage probabilities while the $s_{i+1}$ represent proportion of vacancies filled through promotion into $i+1$ grade. The prediction of flows and stocks as well as the control of grade structures in systems where promotion is restricted to the next higher level has been discussed in details in [6], [7] and [8] among others. In [8], using the Markov theory it was showed that the dual criteria for promotion based on seniority and performance can be modeled in a bivariate framework. The discussion was restricted to systems where promotions take place from a lower level to the next higher level. Apart from [1], [2], [3], [4] and [5], all the other works mentioned earlier are based on the principle of push flow. In systems that operate according to push principles, promotion may occur when there is no vacancy in the system. However, in most systems, the grade sizes are known; promotions only occur to fill vacancies created in the system. Such systems are said to operate according to the pull principle. Models that are based on the Renewal theory are good examples of models that make use of the pull principle. The application of the Renewal model as discussed in [2] is limited to systems where promotions take place from a lower level to the next higher level. A two-stage Renewal process is a Renewal process with two states (stages) in which vacancies created in the second state is filled by moving units from the first state. Movement of units in such a system is limited to single jump since there are only two states. When $\mathrm{k}=1$, that is, there is only one stage, the process reduces to the familiar self-renewing aggregate, the study of which gave rise to modern Renewal theorem, see for example, [9]. This practice of concentrating on single jumps may ignore some transitions inherent in the system. Though [10] and [11] have respectively discussed double jump due to efficiency and double jump due to delay, yet promotions and recruitments were assumed to be expected numbers and thus the expectations of both the promotions and the recruitments could not be determined.

In the present work, we consider modeling of manpower systems such as the ones mentioned earlier where double jumps can occur. A double jump is of interest in this study because in manpower systems, it is more common than other n-jumps $(n \geq 2)$. Promotion and recruitment are defined as random. The expectations and variances of the flows, recruitments and some other important variables were obtained. Earlier authors such as [1] and [2] have defined promotion and recruitment as expectation and concentrated on the prediction and control of grade sizes in manpower systems with single jump processes. They have also assumed that the wastage probability in each grade is constant but here such an assumption is not necessary.

\section{Development of the Model}

lower level to In a Renewal process, the inter-arrival times $t_{i}, i=1,2, \ldots n$ between the jumps are assumed to be independent and identically distributed and the counting process denoting the number of jumps, is defined by $Z(t)=\sup \left(\mathrm{n}: t_{1}+t_{2}+\cdots+t_{n} \leq t\right)$. Similarly, in this work, we assume that the inter-promotion times in which promotions occur are independent and identically distributed. A jump could be promotion from a lower level to the next higher level or from a the next second higher level in one promotion period. We treat promotion and recruitment as random variables and use the Renewal approach to develop flow models that incorporate double jump in a manpower system.

\subsection{Notations}

Let $n_{1}, n_{2}, \ldots, n_{k}$ be the number of units in each level.

$v_{i}=$ The probability of leaving for a unit in level

$W_{j}=$ Number of vacancies observed in level $i$.

$W_{i, j}=$ Number of vacancies in level $\mathrm{j}$ filled through promotion from level $\mathrm{i}$

$s_{i, j}=$ Proportion of vacancies in level $j$ filled by moving units from level $i$.

$F_{k-i, j}(t)=$ The number of promotions from level k-i to level $\mathrm{j}$ in time $\mathrm{t}$.

$$
L_{i}(t)=\text { Number of leavers from grade } \mathrm{i} \text { in time } \mathrm{t} \text {. }
$$

\subsection{Assumptions of the Model}

1. There are $\mathrm{k}$ grades in the system.

2. Movement of employees in the system is either by single or double jump.

3. No employee is expected to jump from a higher level to a lower level.

4. Entry into the system can occur into any level.

5. The grade sizes are known. That is each grade size is constant.

6. $s_{i, j}$ is assumed constant.

\subsection{Formulation of the Model}

If $L_{k}(t)$ is the number of vacancies in level $k$ due to wastage from that level in time $t$, then, the number of single 
jumps from level $k-1$ to replace leavers from level $k$ in time $\mathrm{t}$, is given by,

$$
F_{k-1, k}(t)=L_{k}(t) s_{k-1, k} .
$$

Similarly, the number of double jumps into the last level $k$, can be predicted by,

$$
F_{i, j}(t)=\left[L_{j}(t)+F_{j, j+1}(t)+F_{j, j+2}(t)\right] s_{i, j,} i=1,2, \ldots, k-1, j=i+1, i+2
$$

Where, $L_{j}(t)$ is the number of leavers from grade $\mathrm{j}$ in

$$
\begin{gathered}
F_{i, j}(t)=\left[L_{j}(t)+F_{j, j+1}(t)\right] s_{i, j,} i=1,2, \ldots, k-1, j=i+1 . \\
s_{i, j}=\frac{W_{i, j}}{W_{j}}
\end{gathered}
$$

Therefore, the required number of entrants in level $i$ is given by,

$R_{i}(t)=L_{i}(t)+F_{i, i+1}(t)+F_{i, i+2}(t)-F_{i-1, i}(t)-F_{i-2, i}(t)$

If $\mathrm{i}=1$, since no promotion occurs into the first grade,

$$
R_{i}(t)=L_{i}(t)+F_{i, i+1}(t)+F_{i, i+2}(t)
$$

If $\mathrm{i}=2$, then $\mathrm{c}$ takes only one value $(\mathrm{c}=1)$ since double promotion cannot occur into the second grade. That is,

$$
R_{i}(t)=L_{i}(t)+F_{i, i+1}(t)+F_{i, i+2}(t)-F_{i-1, i}(t)
$$

If only single jump is obtainable in the system, (2.8) becomes,

$$
R_{i}(t)=L_{i}(t)+F_{i, i+1}(t)-F_{i-1, i}(t), i=1,2, \ldots, k
$$

and (2.7) becomes,

$$
\begin{aligned}
& R_{i}(t)=L_{i}(t)+F_{i, i+1}(t), i=1,2, \ldots, k \quad(2.10) \\
& P\left[F_{j, j+1}(t)=f_{j, j+1,} F_{j, j+2}(t)=f_{j, j+2}(t), F_{j, j}(t)=f_{j, j}, F_{j, k+1}(t)=f_{j, k+1}\right]=\frac{n_{j !} !\left(p_{j, j+1}^{f_{j, j+1}}\right)\left(p_{j, j+2}^{f_{j, j+2}}\right)\left(p_{j, j}^{f_{j, j}}\right)\left(p_{j, k+1}^{f_{j, k+1}}\right)}{\left(f_{j, j+1}\right) !\left(f_{j, j+2}\right) !\left(f_{j, j}\right) !\left(f_{j, k+1}\right) !}
\end{aligned}
$$

Since $f_{j, k+1}$ gives the value of $F_{j, k+1}(t)$ (number leaving from $\mathrm{j}$ outside the system, earlier defined as, $\left.L_{j}(t)\right)$ and $v_{j}$ was defined as the probability of leaving the system from

$$
P\left[F_{j, j+1}(t)=f_{j, j+1}, F_{j, j+2}(t)=f_{j, j+2}, F_{j, j}(t)=f_{j, j}, L_{j}(t)=l_{j}\right]=\frac{\left(p_{j, j+1}^{f_{j, j+1}}\right)\left(p_{j, j+2}^{f_{j, j+2}}\right)\left(p_{j, j}^{f_{j, j}}\right)\left(v_{j}^{l_{j}}\right)}{\left(f_{j, j+1}\right) !\left(f_{j, j+2}\right) !\left(f_{j, j}\right) !\left(l_{j}\right) !}
$$

The probabilities $p_{j, h}$, for $\mathrm{h}=\mathrm{j}, \mathrm{j}+1, \mathrm{j}+2, \mathrm{k}+1$ can be obtained. To do this, if data were available for over a period of time, the average value of $F_{j, h}(t)$ can be obtained over the period as, $\overline{f_{J, h}}$. Since $n_{j}$ is assumed fixed, $p_{j, j+1}=\frac{\overline{f_{J, j+1}}}{n_{j}}$, $p_{j, j+2}=\frac{\overline{f_{J, J+2}}}{n_{j}}, p_{j, j}=\frac{\overline{f_{J, j}}}{n_{j}}, v_{j}=\frac{\overline{l_{J}}}{n_{j}}$.

$$
E\left[F_{i, j}\right]=s_{i, j}\left[n_{j} v_{j}+n_{j} p_{j, j+1}+n_{j} p_{j, j+2}\right]
$$

Where $p_{j, j+1}$ is the probability of moving from level $\mathrm{j}$ to $\mathrm{j}+1, p_{j, j+2}$ is the probability of moving from level $\mathrm{j}$ to $\mathrm{j}+2$. The variance of $F_{i, j}(t)$ is given as,

Thus, from (2.13)

$$
\begin{gathered}
V\left[F_{i, j}(t)\right]=V\left\{\left[L_{j}(t)+\sum_{h=j+1}^{j+2} F_{j, h}(t)\right] s_{i, j}\right\}, j=i+1, i+2 \\
V\left[F_{i, j}(t)\right]=s_{i, j}^{2} V\left[L_{j}(t)+\sum_{h=j+1}^{j+2} F_{j, h}(t)\right] \\
V\left[F_{i, j}(t)\right]=s_{i, j}^{2}\left[V\left(L_{j}(t)\right)+V\left(F_{j, j+1}(t)\right)+V\left(F_{j, j+2}(t)\right)+2 \operatorname{Cov}\left(F_{(j, j+1)}(t), F_{(j, j+2)}(t)\right)+2\left(\sum_{\mathrm{h}=\mathrm{j}+1}^{j+2} \operatorname{Cov}\left(L_{j}(t), F_{j, \mathrm{~h}}(t)\right)\right)\right] \\
V\left[F_{i, j}(t)\right]=s_{i, j}^{2}\left[n_{j} v_{j}\left(1-v_{j}\right)+n_{j} p_{j, j+1} q_{j, j+1}+n_{j} p_{j, j+2} q_{j, j+2}-2 n_{j} p_{j, j+1} p_{j, j+2}-2\left(n_{j} v_{j} p_{j, j+1}+n_{j} v_{j} p_{j, j+2}\right)\right]
\end{gathered}
$$




$$
q_{j, j+1}=1-p_{j, j+1} \text { and } q_{j, j+2}=1-p_{j, j+2} .
$$

Let $E\left[R_{i}(t)\right]$ denote the expectation of $R_{i}(t)$, then, from (2.6)

$$
\begin{aligned}
E\left[R_{i}(t)\right] & =E\left[L_{i}(t)\right]+E\left[F_{i, i+1}(t)\right]+E\left[F_{i, i+2}(t)\right]-E\left[F_{i-1, i}(t)\right]-E\left[F_{i-2, i}(t)\right] \\
\mathrm{E}\left[R_{i}(t)\right] & =n_{i} v_{i}+s_{i, j}\left[n_{j} v_{j}+n_{j} p_{j, j+1}+n_{j} p_{j, j+2}\right]-s_{i-c, i}\left[n_{i} v_{i}+n_{i} p_{i, i+1}+n_{i} p_{i, i+2}\right]
\end{aligned}
$$

Let $V\left[R_{i}(t)\right]$ denote the variance of $R_{i}(t)$, then from (2.6),

$$
\begin{gathered}
V\left[R_{i}(t)\right]=V\left[\left[L_{i}\right]+\left[F_{i, i+1}(t)+F_{i, i+2}\right]-\left[F_{i, i-1}(t)+F_{i, i-2}\right]\right] \\
V\left[R_{i}(t)\right]=V\left[L_{i}(t)\right]+V\left(F_{i, i+1}(t)\right)+V\left(F_{i, i+2}(t)\right)+2 \operatorname{cov}\left[F_{i, i+1}(t), F_{i, i+2}(t)\right]+V\left(F_{i-1, i}(t)\right)+V\left(F_{i-2, i}(t)\right) \\
+2 \operatorname{cov}\left[F_{i-1, i}(t), F_{i-2, i}(t)\right]+2 \operatorname{Cov}\left(L_{i}(t), \sum_{j=i+1}^{i+2} F_{i, j}(t)\right)-2 \operatorname{Cov}\left(L_{i}(t), \sum_{c=1}^{2} F_{i-c, i}(t)\right)-2 \sum_{j=i+1}^{i+2} \sum_{c=1}^{2} \operatorname{Cov}\left(F_{i, j}(t), F_{i-c, i}(t)\right.
\end{gathered}
$$

Where the terms in (2.23) can be obtained from (2.19).

Let $n_{i}(t)$ denote the grade size in level $\mathrm{i}$ in time $\mathrm{t}$, then,

$$
\begin{gathered}
n_{i}(t)=n_{i}-\sum_{j=i+1}^{i+2} F_{i, j}(t)+\sum_{c=1}^{2} F_{i-c, i}(t)-L_{i}(t)+R_{i}(t) \\
n_{i}(t)=n_{i}-F_{i, i+1}(t)-F_{i, i+2}(t)+F_{i-1, i}(t)+F_{i-2, i}(t)-L_{i}(t)+R_{i}(t)
\end{gathered}
$$

Let $E\left[n_{i}(t)\right]$ denote the expectation of $n_{i}(t)$, then,

$$
\begin{gathered}
E\left[n_{i}(t)\right]=E\left[n_{i}-F_{i, i+1}(t)-F_{i, i+2}(t)+F_{i-1, i}(t)+F_{i-2, i}(t)-L_{i}(t)+R_{i}(t)\right. \\
E\left[n_{i}(t)\right]=E\left[n_{i}\right]-E\left[F_{i, i+1}(t)\right]-E\left[F_{i, i+2}(t)\right]+E\left[F_{i-1, i}(t)\right]+E\left[F_{i-2, i}(t)\right]-E\left[L_{i}(t)\right]+E\left[R_{i}(t)\right]
\end{gathered}
$$

Since $n_{i}$ is fixed, $\left[n_{i}\right]=n_{i}$, so that,

$$
E\left[n_{i}(t)\right]=n_{i}-E\left[F_{i, i+1}(t)\right]-E\left[F_{i, i+2}(t)\right]+E\left[F_{i-1, i}(t)\right]+E\left[F_{i-2, i}(t)\right]-E\left[L_{i}(t)\right]+E\left[R_{i}(t)\right]
$$

Let $V\left[n_{i}(t)\right]$ denote variance of $n_{i}(t)$, then

$$
V\left[n_{i}(t)\right]=V\left[n_{i}-F_{i, i+1}(t)-F_{i, i+2}(t)+F_{i-1, i}(t)+F_{i-2, i}(t)-L_{i}(t)+R_{i}(t)\right]
$$

$V\left[n_{i}(t)\right]=$

$V\left[n_{i}\right]+V\left[F_{i, i+1}(t)\right]+V\left[F_{i, i+2}(t)\right]+V\left[F_{i-1, i}(t)\right]+V\left[F_{i-2, i}(t)\right]+V\left[L_{i}(t)\right]+V\left[R_{i}(t)\right]-2 \operatorname{Cov}\left[n_{i}, F_{i, i+1}(t)\right]-$ $2 \operatorname{Cov}\left[n_{i}, F_{i, i+2}(t)\right]+2 \operatorname{Cov}\left[n_{i}, F_{i-1, i}(t)\right]+2 \operatorname{Cov}\left[n_{i}, F_{i-2, i}(t)\right]-2 \operatorname{Cov}\left[n_{i}, L_{i}(t)\right]+2 \operatorname{Cov}\left[n_{i}, R_{i}(t)\right]+$ $2 \operatorname{Cov}\left[F_{i, i+1}(t), F_{i, i+2}(t)\right]-2 \operatorname{Cov}\left[F_{i, i+1}(t), F_{i-1, i}(t)\right]-2 \operatorname{Cov}\left[F_{i, i+1}(t), F_{i-2, i}(t)\right]+2 \operatorname{Cov}\left[F_{i, i+1}(t), L_{i}(t)\right]-$ $2 \operatorname{Cov}\left[F_{i, i+1}(t), R_{i}(t)\right]-2 \operatorname{Cov}\left[F_{i, i+2}(t), F_{i-1, i}(t)\right]-2 \operatorname{Cov}\left[F_{i, i+2}, F_{i-2, i}(t)\right]+2 \operatorname{Cov}\left[F_{i, i+2}(t), L_{i}(t)\right]-$ $2 \operatorname{Cov}\left[F_{i, i+2}(t), R_{i}(t)\right]+2 \operatorname{Cov}\left[F_{i-1, i}(t), F_{i-2, i}(t)\right]-\operatorname{Cov}\left[F_{i-1, i}(t), L_{i}(t)\right]+2 \operatorname{Cov}\left[F_{i-1, i}(t), R_{i}(t)\right]-$ $2 \operatorname{Cov}\left[F_{i-2, i}(t), L_{i}(t)\right]+2 \operatorname{Cov}\left[F_{i-2, i}(t), R_{i}(t)\right]-2 \operatorname{Cov}\left[L_{i}(t), R_{i}(t)\right]$

Since each $n_{i}$ is constant, the covariance between it and the other components in $V\left[n_{i}(t)\right]$ is zero. We assume that leaving and promotion take place before recruitment, so

that the leaving process and promotion are independently distributed with the recruitment. Therefore,

$$
\begin{aligned}
& V\left[n_{i}(t)\right]=V\left[F_{i, i+1}(t)\right]+V\left[F_{i, i+2}(t)\right]+V\left[F_{i-1, i}(t)\right]+V\left[F_{i-2, i}(t)\right]+V\left[L_{i}(t)\right]+2 \operatorname{Cov}\left[F_{i, i+1}(t), F_{i, i+2}(t)\right]- \\
& 2 \operatorname{Cov}\left[F_{i, i+1}(t), F_{i-1, i}(t)\right]-2 \operatorname{Cov}\left[F_{i, i+1}(t), F_{i-2, i}(t)\right]+2 \operatorname{Cov}\left[F_{i, i+1}(t), L_{i}(t)\right]-2 \operatorname{Cov}\left[F_{i, i+2}(t), F_{i-1, i}(t)\right]- \\
& 2 \operatorname{Cov}\left[F_{i, i+2}, F_{i-2, i}(t)\right]+2 \operatorname{Cov}\left[F_{i-1, i}(t), F_{i-2, i}(t)\right]-\operatorname{Cov}\left[F_{i-1, i}(t), L_{i}(t)\right]-2 \operatorname{Cov}\left[F_{i-2, i}(t), L_{i}(t)\right]+V\left[R_{i}(t)\right]
\end{aligned}
$$

From (2.23), it is evident that $V\left[n_{i}(t)\right]$ is two times $\left[R_{i}(t)\right]$.

\subsection{Maintainability of Structures}

In this section, we examine the maintainability of a manpower system with double jump. We use the Renewal approach for the development of the models. We shall among others specify recruits into the system in terms of the proportion of vacancies to be filled by the recruits rather than the proportion of recruits to be allocated to that level as is the case with the Markov model, see for example, [5]

Let $\alpha$ be the expansion rate of the system and let $q$ denote the relative size of the system where single and double jumps can occur.

Let $s_{i}$ be the proportion of vacancies filled by promotion into level $i$. 
The total number of vacancies $T_{i}$ to be filled by new entry into level $i$, is

$T_{i}=\left[L_{i}(t)+F_{i, i+1}(t)+F_{i, i+2}(t)+n_{i} \alpha\right]\left(1-s_{i}\right)$

Where $1-s_{i}$ is the proportion of vacancies filled by new entry into level $i$. In practice,

$$
s_{i}=s_{i-1, i}+s_{i-2, i}
$$

Where, $s_{i-1, i}$ is the proportion of vacancies filled through promotion in the past from level i-1 to level $\mathrm{i}$ and $s_{i-2, i}$ is the proportion of vacancies filled through promotion in the past from level i-2 to level $\mathrm{i}$.

If only single jump is applicable in the system, then,

$$
T_{i}=\left[L_{i}(t)+F_{i, i+1}(t)+n_{i} \alpha\right]\left(1-s_{i}\right)
$$

With an expansion rate $\alpha$ in the system, the total vacancy in the system,

$$
T=\sum_{i=1}^{k} L_{i}(t)+N \alpha
$$

Dividing (2.34) by(2.35), we obtain,

$$
\frac{T}{T^{l}}=\frac{\left[\mathrm{L}_{\mathrm{i}}(\mathrm{t})+\sum_{j=i+1}^{i+2} F_{i, j}(\mathrm{t})+\mathrm{n}_{\mathrm{i}} \alpha\right]\left(1-\mathrm{s}_{\mathrm{i}}\right)}{\sum_{\mathrm{i}=1}^{\mathrm{k}} \mathrm{L}_{\mathrm{i}}(\mathrm{t})+\mathrm{N} \alpha}
$$

Since we are interested in the relative size of the system, we further divide the numerator and denominator of (2.36) by $\mathrm{N}$ to obtain,

$$
r_{i}=\frac{\left[\frac{L_{i}(t)}{N}+\left(\frac{F_{j, j+1}(t)+F_{j, j+2}(t)}{N}\right)+q_{i} \alpha\right]\left(1-s_{i}\right)}{\frac{\sum_{i=1}^{k} L_{i}(t)}{N}+\alpha}
$$

This is the proportion of vacancies to be filled by entry into level.

Where, $q_{i}=\frac{n_{i}}{N}$. then,

If only single jump is applicable in the system,

$$
r_{i}=\frac{\left[\frac{L_{i}(t)}{N}+F_{i, i+1}(t) / N+q_{i} \alpha\right]\left(1-s_{i}\right)}{\frac{\sum_{i=1}^{k} L_{i}(t)}{N}+\alpha}
$$

In order to evaluate the proportion of vacancies in level $\mathrm{j}$ to be filled by movement from a lower level $i$, we adjust (2.3) to include the expansion term $n_{j} \alpha$ and divide by the number of units in level $i$, to obtain,

the proportion of units to be moved from level $i$ to level $j$,

$$
p_{i, j}=\frac{\left[L_{j}(t)+n_{j} \alpha+F_{j, j+1}(t)+F_{j, j+2}(t)\right] s_{i, j}}{n_{i}}
$$

Dividing both the numerator and denominator of (3.46) by $\mathrm{N}$, we obtain,

$$
p_{i, j}=\frac{\left[\frac{L_{j}(t)}{N}+q_{j} \alpha+\left(\frac{F_{j, j+1}(t)+F_{j, j+2}(t)}{N}\right)\right] s_{i, j}}{q_{i}}
$$

This is the relative proportion of units in level $\mathrm{i}$, that is expected to move to level $\mathrm{j}$ in order to maintain the system. Suppose, the system allows only single jump, then,

$$
p_{i, j}=\frac{\left[\frac{L_{j}(t)}{N}+q_{j} \alpha+\left(F_{i, i+1}(t) / N\right)\right] s_{i, i+1}}{q_{i}}
$$

The above derivation is a new form of maintainability of structures via the Renewal model. It differs from the previous ones by allowing the number of promotions to be random, not assuming constant wastage and extends the models to include the case of double jump. The objectives of the models are to examine how expansion of the system affects transitions into and within the system.

From (2.32), the expectation and variance of the total number of vacancies in grade i were obtained as,

$$
\begin{array}{r}
E\left[T_{i}\right]=E\left[L_{i}(t)+\sum_{j=i+1}^{i+2} F_{i, j}(t)+n_{i} \alpha\right]\left(1-s_{i}\right) \\
E\left[T_{i}\right]=\left[n_{i} v_{i}+n_{i} p_{i, i+1}+n_{i} p_{i, i+2}+n_{i} \alpha\right]\left(1-s_{i}\right)
\end{array}
$$

Similarly we obtain the variance of $T_{i}$ as,

$$
V\left[T_{i}\right]=\left(1-s_{i}\right)^{2} V\left[\left\{L_{i}(t)\right\}+\left(F_{i, i+1}(t)+F_{i, i+2}(t)\right)+n_{i} \alpha\right]
$$

Since $V\left\{n_{i} \alpha\right\}=0$

$$
\begin{gathered}
V\left[T_{i}\right]=\left(1-s_{i}\right)^{2}\left[V\left\{L_{i}(t)\right\}+V\left\{F_{i, i+1}(t)\right\}+V\left\{F_{i, i+2}(t)\right\}+2 \operatorname{Cov}\left\{F_{i, i+1}(t), F_{i, i+2}(t)\right\}+2 \sum_{j=i+1}^{i+2} \operatorname{Cov}\left(L_{i}(t), F_{i, j}(t)\right)\right] \\
V\left[T_{i}\right]=\left(1-s_{i}\right)^{2}\left[n_{i} v_{i}\left(1-v_{i}\right)+n_{i} p_{i, i+1} q_{i, i+1}+n_{i} p_{i, i+2} q_{i, i+2}-2 n_{i} p_{i, i+1} p_{i, i+2}-2\left(n_{i} v_{i} p_{i, i+1}+n_{i} v_{i} p_{i, i+2}\right)\right]
\end{gathered}
$$

If only single jump is obtainable in the system, the corresponding expectation and variance of $T_{i}$ can be obtained from (2.34) respectively as,

$$
E\left[T_{i}\right]=\left[n_{i} v_{i}+n_{i} p_{i, i+1}+n_{i} \alpha\right]\left(1-s_{i}\right)
$$

and

$V\left[T_{i}\right]=\left(1-s_{i}\right)^{2}\left[n_{i} v_{i}\left(1-v_{i}\right)+n_{i} p_{i, i+1} q_{i, i+1}-\right.$ $\left.2 n_{i} v_{i} p_{i, i+1}\right]$
We can also obtain the expectation and variance of $r_{i}$ in (2.37). Thus, the expectation of $r_{i}$ was obtained from,

$$
E\left[r_{i}\right]=E\left\{\frac{\left[\frac{L_{i}}{N}+\frac{\sum_{j=i+1}^{i+2} F_{i, j}(t)}{N}+q_{i} \alpha\right]\left(1-s_{i}\right)}{\frac{\sum_{i=1}^{k} L_{i}}{N}+\alpha}\right\}
$$

Since, $\mathrm{N}$ is constant; we can obtain $E\left(r_{i}\right)$ from (2.36). That is, $E\left[r_{i}\right]=E\left[\frac{T_{i}}{T}\right]$

It was observed in [12] that, in general, there are no 
simple exact formulars for the mean and variance of the quotient of two random variables in terms of the moments of the two variables but that some approximate formulars such as the Taylor series can be used. Thus, we use the
Taylor's series expansion to obtain an approximation of $E\left(\frac{T_{i}}{T}\right)$. Hence,

$$
\begin{array}{lr}
f\left(T_{i}+\mu_{T_{i}}, T+\mu_{T}\right)=f\left(T_{i}, T\right)+\left(\frac{\partial f\left(T_{i}, T\right)}{\partial T_{i}}\right) \mu_{T_{i}}+\frac{\partial f\left(T_{i}, T\right)}{\partial T} \mu_{T}+\frac{1}{2}\left[\frac{\partial^{2} f\left(T_{i}, T\right)}{\partial T_{i}^{2}} \mu_{T_{i}}+2 \frac{\partial^{2} f\left(T_{i}, T\right)}{\partial T_{i} \partial T} \mu_{T_{i}} \mu_{T}+\frac{\partial^{2} f\left(T_{i}, T\right)}{\partial T^{2}} \mu_{T}\right. \\
f\left(T_{i}+\mu_{T_{i}}, T+\mu_{T}\right)=\frac{\mu_{T_{i}}}{\mu_{T}}+\frac{T_{i}}{\mu_{T}}-\frac{\mu_{T_{i} T}}{\mu_{T}^{2}}-\frac{T T_{i}}{\mu_{T}^{2}}+\frac{T^{2} \mu_{T_{i}}}{\mu_{T}^{3}}(2.51) & E\left[\frac{T_{i}}{T}\right]=\frac{\mu_{T i}}{\mu_{T}}-\frac{\operatorname{Cov}\left(T_{i}, T\right)}{\mu_{T}^{2}}+\frac{V(T) \mu_{T_{i}}}{\mu_{T}^{3}} \\
f\left(T_{i}+\mu_{T_{i}}, T+\mu_{T}\right)=\frac{\mu_{T_{i}}}{\mu_{T}}+\frac{T_{i} \mu_{T}-\mu_{T_{i} T}}{\mu_{T}^{2}}-\frac{T_{i} T}{\mu_{T}^{2}}+\frac{T^{2} \mu_{T_{i}}}{\mu_{T}^{3}}(2.52) & E\left(\frac{T_{i}}{T}\right)=\frac{\mu_{T_{i}}}{\mu_{T}}-\frac{E\left(T_{i}, T\right)}{\mu_{T}^{2}}+\left[\frac{V(T)+(E(T))^{2}}{\mu_{T}^{3}}\right. \\
\text { If } T_{i} \text { and } T \text { are random variables with finite expectations } & E\left[\frac{T_{i}}{T}\right] \cong \frac{E\left[T_{i}\right]}{E[T]}-\frac{1}{[E[T]]^{2}} \operatorname{Cov}\left[T_{i}, T\right]+\frac{E\left[T_{i}\right]}{[E[T]]^{2}} V \\
\mu_{T_{i}} \text { and } \mu_{T} \text { and if } T \neq 0 \text {, then }
\end{array}
$$

$$
\begin{gathered}
E\left[\frac{T_{i}}{T}\right]=\left[\frac{\mu_{T_{i}}}{\mu_{T}}\right]-\frac{E\left(T_{i} T\right)}{\mu_{T}^{2}}+\frac{V(T) \mu_{T_{i}}}{\mu_{T}^{3}}+\frac{[E(T)]^{2} \mu_{T_{i}}}{\mu_{T}^{3}} \\
V\left[\frac{T_{i}}{T}\right] \cong V\left[T_{i}\right]\left[\frac{\partial}{\partial T_{i}} f\left(T_{i}, T\right)\right]^{2}+V(T) \quad \text { Similarly, the variance was obtained, } \\
V\left[\frac{\partial}{d T} f\left(T_{i}, T\right)\right]^{2}+2 \operatorname{cov}\left[T_{i}, T\right]\left[\frac{\partial}{\partial T_{i}} f\left(T_{i}, T\right) \times \frac{\partial}{\partial T} f\left(T_{i}, T\right)\right. \\
V\left[r_{i}\right]=V\left[\frac{\left.T_{i}\right]}{T}\right] \cong\left(\frac{E\left[T_{i}\right]}{E[T]}\right)^{2}\left\{\frac{V[T]\left[E\left[T_{i}\right]^{2}\right.}{\left[E[T]^{4}\right.}-\frac{2 E\left[T_{i}\right] \operatorname{cov}\left(T_{i}, T\right)}{\left[E[T]^{3}\right.}\right. \\
\left(E\left[T_{i}\right]\right)^{2} \\
\end{gathered}
$$

From (2.48), it is easy to see that,

$$
\begin{aligned}
& E\left[p_{i, j}\right]=E\left\{\frac{\left[\frac{L_{j}(t)}{N}+q_{j} \alpha+\left(\sum_{j+1}^{j+2} F_{j, h}(t) / N\right) s_{i, j}\right.}{q_{i}}\right\} \\
& E\left(p_{i, j}\right)=\left[\frac{\frac{n_{j} v_{j}}{N}+q_{j} \alpha+\frac{n_{j} p_{j, j+1}+n_{j} p_{j, j+2}}{N}}{q_{i}}\right] s_{i, j} \\
& V\left(p_{i, j}\right)=\frac{s_{i, j}^{2}}{q_{i}^{2}} V\left[\frac{L_{j}}{N}+q_{j} \alpha+\frac{\sum_{j+1}^{j+2} F_{j, h}(t)}{N}\right] \\
& V\left(p_{i, j}\right)=\frac{s_{i, j}^{2}}{q_{i}^{2}}\left[\frac{n_{j} v_{j}}{N^{2}}+\frac{1}{N^{2}} V\left(\sum_{j+1}^{j+2} F_{j, h}(t)\right)+\frac{2}{N} \operatorname{Cov}\left(\frac{L_{j}}{N}, \sum_{j+1}^{j+2} F_{j, h}(\mathrm{t})\right)\right] \\
& V\left[p_{i, j}\right]=\frac{s_{i, j}^{2}}{q_{i}^{2}}\left[\frac{n_{j} v_{j}}{N^{2}}+\frac{1}{N^{2}}\left(n_{j} p_{j, j+1} q_{j+1}+n_{j} p_{j, j+2} q_{j, j+2}\right)-2 n_{j} p_{j, j+1} p_{j, j+2}-\frac{2 n_{j}}{N}\left(n_{j} v_{j} p_{j, j+1}+n_{j} v_{j} p_{j, j+2}\right)\right]
\end{aligned}
$$

$$
\begin{gathered}
E[T]=\sum_{i=1}^{k} n_{i} v_{i}+N \alpha \\
V[T]=\sum_{i}^{k} V\left(L_{i}\right)
\end{gathered}
$$

Validating of the Predictive Models for Promotion

The objective of this section is to provide the statistic that will be used to test the validity of the flow model given by

$$
F_{i, j}(t)=\left[L_{j}+\left(\sum_{h=j+1}^{j+2} F_{j, h}(t)\right)\right] s_{i, j}, i=1,2, \ldots, k-1 .
$$

We shall use the test statistic,

$$
\chi^{2}=\sum_{i=\frac{\left(O_{i}-P_{i}\right)^{2}}{P_{i}}}
$$

Where, $O_{i}$ and $P_{i}$ are the observed and predicted flows in ith grade respectively.

The statistic in (2.67) has Chi-square distribution with k-1 degrees of freedom, and $\mathrm{k}$ is the number of cells in the table. Our aim here is to find out if the model adequately fits the system.

\section{Application of the Models}

In this chapter, the predictive and control models developed in this paper were applied to data collected from a manpower system. Results were obtained and interpreted. The flow model was validated by using the predicted flows and the observed flows to test for the adequacy of the model with the aid of a Chi-square test statistic.

Specifically, the models were applied to data collected from Standard Life Insurance Nigeria in 2009. Standard Life Insurance Company is an organization with about forty-one (41) branches all over the country. The strength of the manpower is about one thousand, six hundred and thirty five $(1,635)$. The categories of staff in the manpower system are Marketing executive, Field manager, Unit manager, Retail head, Branch manager, Regional manager, Divisional manager, General manager and Director.

In Standard Life Insurance Company, hard work and creativeness are the basis for promotion.

\subsection{Data Presentation}

The data used in this study were presented in Table 3.1. 
Table 3.1. Data Collected from Standard Life Insurance Company: Stock data $n(t-1)$, Observed Wastage $L_{i}(t)$, Observed Vacancy $W_{j}$ and Wastage Probability $v_{i}$

\begin{tabular}{|c|c|c|c|c|c|c|c|c|c|}
\hline Level & $\begin{array}{l}\text { Marketing } \\
\text { Executive }\end{array}$ & $\begin{array}{l}\text { Field } \\
\text { Manager }\end{array}$ & $\begin{array}{l}\text { Unit } \\
\text { Manager }\end{array}$ & $\begin{array}{l}\text { Retail } \\
\text { Head }\end{array}$ & $\begin{array}{l}\text { Branch } \\
\text { Manager }\end{array}$ & $\begin{array}{l}\text { Regional } \\
\text { Manager }\end{array}$ & $\begin{array}{l}\text { Divisional } \\
\text { Manager }\end{array}$ & $\begin{array}{l}\text { General } \\
\text { Manager }\end{array}$ & Director \\
\hline Stockn $(t-1)$ & 930 & 465 & 155 & 36 & 31 & 8 & 5 & 2 & 3 \\
\hline$L_{i}(t)$ & 62 & 31 & 7 & 4 & 3 & 3 & 2 & 1 & 2 \\
\hline$W_{j}$ & 235 & 118 & 39 & 13 & 17 & 3 & 2 & 2 & 2 \\
\hline$v_{i}$ & 0.067 & 0.067 & 0.045 & 0.11 & 0.097 & 0.38 & 0.4 & 0.5 & 0.67 \\
\hline
\end{tabular}

Observed Vacancies filled through Promotion from Level $\mathrm{i}$ to Level $\mathrm{j}$

$W_{i, j}=\left[\begin{array}{ccccccccc}0 & 30 & 11 & 0 & 0 & 0 & 0 & 0 & 0 \\ 0 & 0 & 15 & 4 & 0 & 0 & 0 & 0 & 0 \\ 0 & 0 & 0 & 7 & 3 & 0 & 0 & 0 & 0 \\ 0 & 0 & 0 & 0 & 12 & 0 & 0 & 0 & 0 \\ 0 & 0 & 0 & 0 & 0 & 1 & 0 & 0 & 0 \\ 0 & 0 & 0 & 0 & 0 & 0 & 1 & 0 & 0 \\ 0 & 0 & 0 & 0 & 0 & 0 & 0 & 1 & 0 \\ 0 & 0 & 0 & 0 & 0 & 0 & 0 & 0 & 1 \\ 0 & 0 & 0 & 0 & 0 & 0 & 0 & 0 & 0\end{array}\right]$

\subsection{Estimation of the Proportions of Vacancies filled through Promotion}

In this section, we estimate the proportion of vacancies filled through promotion $\left(s_{i, j}\right)$

Applying (2.6) to data on observed vacancies and vacancies filled through promotion.

The proportions of vacancies filled through promotions were estimated as

$$
\begin{aligned}
& s_{1,2}=0.25, s_{1,3}=0.28, s_{2,3}=0.38, s_{2,4}=0.31 \\
& s_{3,4}=0.54, s_{3,5}=0.18, s_{4,5}=0.71, s_{5,6}=0.33 \\
& s_{6,7}=0.5, s_{7,8}=0.5, s_{8,9}=0.5
\end{aligned}
$$

The results show that more of the vacancies in the fifth level were filled through promotion. The results also show that only small proportions of vacancies were filled through promotion in the lower levels.

$$
\begin{array}{r}
p_{1,2}=0.01, \quad p_{1,3}=0.004, \quad p_{2,3}=0.01, \\
p_{4,5}=0.088, \quad p_{5,6}=0.0479, \quad p^{2},
\end{array}
$$

The results show that the transitional probabilities are higher at the higher levels. Further examination of the results shows that the probabilities of double jumps are smaller than the probabilities of single jumps. Thus, this shows that employees who have double jumps are fewer than employees who have single jumps.

\subsection{Prediction of Promotion Flows}

Using (2.3), the promotion flows into each level were predicted. We used (2.15) to obtain the expected values of the promotion flows. The expected values obtained were seen to be equal to the predicted values in time $t$.

The variances of the predicted flows were obtained using (2.19) and consequently the standard errors were obtained.

The predicted flows are given below with their standard errors in parenthesis. For simplicity, only the non-zero predicted flows are given here.

$$
\begin{array}{ll}
F_{8,9}=1(0.709), & F_{7,8}=1(0.613) \\
F_{6,7}=1.5(0.771), & F_{5,6}=1.485(0.629) \\
F_{4,5}=3.184(1.31), & F_{3,5}=0.807(0.332) \\
F_{3,4}=3.88(1.286), & F_{2,4}=2.227(0.735) \\
F_{2,3}=4.441(1.122), & F_{1,3}=3.272(0.827), F_{1,2}=9.417(1.435)
\end{array}
$$

The above results show that the predicted promotion flows represent only small proportions of the stocks from which they originated. The highest promotion flow in the system is from Marketing Executive to Field Manager, followed by promotion from Field Manager to unit manager. Dividing each flow by the stock in which it originated from, we obtain the transitional probabilities as,

\subsection{Prediction of Recruitments}

$$
\begin{aligned}
& R_{1}=74.689(8.06), R_{2}=28.251(5.738), R_{3}=3.974(3.26), R_{4}=1.078(2.81), R_{5}=0.493(2.29), \\
& R_{6}=3.015(2.007), R_{7}=1.5(1.723), R_{8}=1(1.23), \quad R_{9}=1(1.418)
\end{aligned}
$$

The above results show that the recruitment is highest at the lowest level (Marketing Executive). The high recruitment needs in the lowest level is often the case in most manpower systems because only experienced staff are recruited in the higher levels. The standard errors of the recruitments are high at the lower levels but decreases considerably at the higher levels. This is because, most recruits are taken at the lower level and the number varies 
according to the manpower needs of the organization. However, we observed that, the recruitment needs into each level decreased down the hierarchy but increased in level 6(Regional Manager), this may mean that most of the employees retire at that level.

After predicting the promotion and recruitment needs for time $t$, the number of employees (the stocks) in each level was obtained using (2.25). The following results were obtained:

$$
n(t)=\left[\begin{array}{lllllllll}
930 & 465 & 155 & 36 & 31 & 8 & 5 & 2 & 3
\end{array}\right]
$$

The above results show that the grade sizes in time $t$ are the same with the initial grade sizes. This result is expected since promotions and recruitments occur into the levels to fill vacancies created in the levels.

\subsection{Application of the Maintainability Models}

In this section, the control models developed in the Chapter three are applied to data. We obtain both recruitment and promotion in terms of proportions of vacancies to be filled through recruitment and promotion respectively. The results are obtained for $0 \%, 5 \%$ and $10 \%$ expansion rates in the system. Using (2.33) we obtain,

$\mathrm{s}_{1}=0, \mathrm{~s}_{2}=0.25, \mathrm{~s}_{3}=0.66, \mathrm{~s}_{4}=0.85, \mathrm{~s}_{5}=0.89, \mathrm{~s}_{6}=0.33$, $\mathrm{s}_{7}=0.5, \mathrm{~s}_{8}=0.5$

By expressing the number of employees in each level as a proportion of the total size of the system, we obtain,

$\mathrm{q}=\left[\begin{array}{lllllll}0.569 & 0.284 & 0.095 & 0.022 & 0.019 & 0.005 & 0.003\end{array}\right.$ $0.0010 .002]$

Using (2.43), we obtain the expected number of vacancies in each grade. The results are given in Table 3.2.

Table 3.2. Expected Number of Vacancies in Each Grade at Different Expansion Rates.

\begin{tabular}{cllll}
\hline $\begin{array}{l}\text { Total } \\
\text { Vacancies in } \\
\text { Level i }\end{array}$ & $\begin{array}{l}\text { Observed } \\
\text { Vacancies }\end{array}$ & $\boldsymbol{\alpha}=\mathbf{0}$ & $\boldsymbol{\alpha}=\mathbf{0 . 0 5}$ & $\boldsymbol{\alpha}=\mathbf{0 . 1}$ \\
\hline$T_{1}$ & 235 & 74.999 & 121.499 & 167.999 \\
$T_{2}$ & 118 & 28.367 & 45.805 & 63.242 \\
$T_{3}$ & 39 & 3.965 & 6.6 & 9.235 \\
$T_{4}$ & 13 & 1.072 & 1.342 & 1.612 \\
$T_{5}$ & 17 & 0.494 & 0.665 & 0.835 \\
$T_{6}$ & 3 & 3.042 & 3.31 & 3.578 \\
$T_{7}$ & 2 & 1.5 & 1.625 & 1.75 \\
$T_{8}$ & 2 & 1 & 1.05 & 1.1 \\
$T_{9}$ & 2 & 1.005 & 1.08 & 1.155 \\
\hline
\end{tabular}

The standard errors of the expected vacancies were obtained from (2.46) as s.e $\left(T_{1}\right)=8.32, \operatorname{s.e}\left(T_{2}\right)=4.437$, s.e $\left(T_{3}\right)=1.148, \operatorname{s.e}\left(T_{4}\right)=0.3586$, s.e $\left(T_{5}\right)=0.216$, s.e $\left(T_{6}\right)=0.939$, s.e $\left(T_{7}\right)=0.548$, s.e $\left(T_{8}\right)=0.559$, s.e $\left(T_{9}\right)=0.407$. The results show that the predictions of vacancies at the lower levels are associated with more errors than predictions at the higher levels.

Using(2.37) and (2.40), the proportions of vacancies to be filled through recruitments and promotions were obtained and given in Table 3.3 and Table 3.4 respectively.
Table 3.3. Proportions of Vacancies to be filled through recruitment.

\begin{tabular}{llll}
\hline $\begin{array}{l}\text { Recruitment } \\
\left(\mathrm{r}_{\mathrm{i}}(\mathrm{t})\right)\end{array}$ & Proportions & & \\
\hline & $\alpha=0.00$ & $\alpha=0.05$ & $\alpha=0.1$ \\
$\mathrm{r}_{1}$ & 0.65 & 0.616 & 0.602 \\
$\mathrm{r}_{2}$ & 0.25 & 0.23 & 0.2292 \\
$\mathrm{r}_{3}$ & 0.03 & 0.034 & 0.033 \\
$\mathrm{r}_{4}$ & 0.009 & 0.007 & 0.006 \\
$\mathrm{r}_{5}$ & 0.005 & 0.0034 & 0.003 \\
$\mathrm{r}_{6}$ & 0.03 & 0.017 & 0.013 \\
$\mathrm{r}_{7}$ & 0.013 & 0.0048 & 0.006 \\
$\mathrm{r}_{8}$ & 0.008 & 0.005 & 0.004 \\
$\mathrm{r}_{9}$ & 0.009 & 0.006 & 0.005 \\
\hline
\end{tabular}

Table 3.3 shows that the proportions of vacancies to be filled through recruitment are highest at the first two lower levels. It is observed that as the system is expanded, the proportion of vacancies to be filled through recruitment decreases than the hierarchy. This shows that expansion in the total size of the system increases promotion opportunities. The proportions of vacancies to be filled through recruitments into the higher levels are smallest when the system is expanded by $10 \%$ except in level 7(Divisional Manager) where the proportion increased. This increase in the proportion of vacancies to be filled through recruitment in Level 7, may be due to the increase in the recruitment needs in Level 6 earlier observed, which may not afford the management, the opportunity to get enough experienced employees to be promoted to Level 7. This may then lead to more recruitment of experienced employees into the grade.

Table 3.4 shows that as the system is expanded, the proportions of vacancies to be filled through promotion tend to increase in all the levels. This shows that promotion difficulty at the higher levels can be removed by expanding the system relative to the total size of the system. The proportions of units moving up the hierarchy are highest at $10 \%$ expansion of the system.

Table 3.4. Proportions of vacancies to be filled through promotion.

\begin{tabular}{llll}
\hline Promotion $\left(\mathbf{p}_{\mathbf{i}, \mathbf{j}}(\mathbf{t})\right)$ & \multicolumn{3}{c}{ Proportions } \\
\hline & $\alpha=0.00$ & $\alpha=0.05$ & $\alpha=0.1$ \\
$\mathrm{p}_{1,2}$ & 0.01 & 0.016 & 0.023 \\
$\mathrm{p}_{1,3}$ & 0.003 & 0.006 & 0.008 \\
$\mathrm{p}_{2,3}$ & 0.00956 & 0.014 & 0.022 \\
$\mathrm{p}_{2,4}$ & 0.005 & 0.006 & 0.0072 \\
$\mathrm{p}_{3,4}$ & 0.025 & 0.031 & 0.037 \\
$\mathrm{p}_{3,5}$ & 0.005 & 0.007 & 0.0088 \\
$\mathrm{p}_{4,5}$ & 0.0885 & 0.119 & 0.15 \\
$\mathrm{p}_{5,6}$ & 0.16 & 0.165 & 0.1609 \\
$\mathrm{p}_{6,7}$ & 0.18 & 0.198 & 0.213 \\
$\mathrm{p}_{7,8}$ & 0.19 & 0.212 & 0.221 \\
$\mathrm{p}_{8,9}$ & 0.51 & 0.5375 & 0.575 \\
\hline
\end{tabular}

\subsection{Validity of the Predictive Models for Promotion}

In order to find out if the Promotion Flow model adequately fits the manpower system of the organization, we use (2.67) to test for the validity of the model. The following hypotheses are to be tested:

Null Hypothesis $\left(\mathrm{H}_{0}\right)$ : The promotion flow models adequately fit the manpower system of the Insurance Company. 
Alternative Hypothesis: The promotion flow models do not adequately fit the manpower of the Insurance Company.

By using the predicted and observed values of the flow in (2.67), we obtained the calculated value of the Chisquare. Using this calculated Chi-square value and a level of significance of 0.05 , we obtained the Probability Value (P) by the aid of the Excel Spread Sheet Package. This P was compared with the level of significance. Each time $\mathrm{P}$ is less than $0.05(\mathrm{P}<0.05)$, we reject the null hypothesis, otherwise, we accept the null hypothesis.

The results are shown in Table 3.5 and Table 3.6

Table 3.5. Predicted Flows and Observed Flows for 2010.

\begin{tabular}{lll}
\hline $\boldsymbol{F}_{i, j}$ & Predicted Values & Observed Values \\
\hline$F_{1,2}$ & 9.417 & 11 \\
$F_{1,3}$ & 3.272 & 3 \\
$F_{2,3}$ & 4.441 & 8 \\
$F_{2,4}$ & 2.227 & 2 \\
$F_{3,4}$ & 3.88 & 7 \\
$F_{3,5}$ & 3.88 & 0 \\
$F_{4,5}$ & 3.184 & 2 \\
$F_{5,6}$ & 1.485 & 1 \\
$F_{6,7}$ & 1.5 & 3 \\
$F_{7,8}$ & 1 & 0 \\
$F_{8,9}$ & 1 & 1 \\
\hline
\end{tabular}

Table 3.6. Validity of the Predictive Flow Model.

\begin{tabular}{llll}
\hline $\begin{array}{l}\text { Predicted } \\
\left(P_{i}\right)\end{array}$ & Values & $\begin{array}{l}\text { Observed } \\
\left(O_{i}\right)\end{array}$ & Values \\
\hline 9.417 & 11 & 0.266 \\
7.713 & 11 & 1.401 \\
9.987 & 9 & 0.098 \\
8.169 & 7 & 0.167 \\
Total & & 1.932 \\
\hline
\end{tabular}

$\mathrm{P}=0.587$.

Since some of the predicted flows are less than 5 , we merge $\mathrm{F}_{1,3}$ and $\mathrm{F}_{2,3} ; \mathrm{F}_{2,4}, \mathrm{~F}_{3,4}$ and $\mathrm{F}_{3,5} ; \mathrm{F}_{4,5}$ and the other flows at the higher levels in Table 3.5 to obtain Table 3.6.

Since $\mathrm{P}>0.05$, the predicted values are not significantly different from the observed values.

The results in table 3.6, above show that $\mathrm{P}>0.05$; thus showing that the promotion flow model provides a good fit to the manpower system.

\section{Conclusion}

In order to find a model that will appropriately describe a manpower system with a known grade structure where both single and double jumps occur, a Renewal theory was employed to describe the flows within the system and the entries into the system. The method employed is such that promotions and recruitments only occur to fill vacancies created in the higher grades. The number of promotions and number of recruitments occurring in the system were allowed to be random so that the variances and expectations of both the promotion flow and the recruitment into each grade could be obtained. Results obtained from the validation of the models show that the predicted promotion flows were not significantly different from the observed flows.

\section{References}

[1] Stewman S. (1978), Markov and Renewal Models for Total Manpower System, Omega Journal, Vol. 6, No.4, 341-351.

[2] Price, W.I., Martel and Lewis, K.A. (1980), A Review of Mathematical Models in Human Resource Planning; Omega, Vol. 5, No. 6, 639-645

[3] Uche P.I. (1984), Models for Some Stochastic Systems, International Journal of Mathematics Education in Science and Technology, Vol. 15, No. 6, pp 737-743.

[4] Sirvanci, M. (1984), Forecasting Manpower losses by the use of Renewal Models, Europeon Journal of Operational Research, Vol.16, No. 4, 13-18.

[5] Bartholomew, D.J., Forbes, A., McClean, S. (1991),Statistical Techniques for Manpower Planning; $2^{\text {nd }}$ edn, Wiley, Chichester 139-146.

[6] Davies, G.S.(1975), Maintainability of Structures in Markov Chain Models Under Recruitment Control; Journal of Applied Probability, Vol. 12, 376 - 382.

[7] Ossai, E.O. (2008), Statistical Control Models in Graded and Departmentalized Manpower System, Ph. D Thesis, Department of Statistics, University of Nigeria, Nsukka.

[8] Raghavendra B.(1991), A Bivariate Model for Markov Manpower Planning Systems, Journal of Operational Research Society Vol.12, 565-570.

[9] Bartholomew, D.J. (1963a), A Multi-Stage Renewal Process, Journal of Royal Statistical Society, B25, 150 - 168.

[10] Nwaigwe C.C. (2011), A Renewal Theoretical Model for Double Jump in Graded Manpower System, Journal of Nigerian Statistical Association, Vol. 23, 22-35

[11] Nwaigwe C. C. (2011), A renewal model with Duration in a grade for manpower Planning, Journal of Interdisciplinary Mathematics, Vol. 14, 463-469.

[12] Mood A. M., Graybill F. A. and Boes C. D. (1962).Introduction to the Theory of Statistics, $3^{\text {rd }}$ ed., Mc Gray-Hill series. 